\title{
Diversity of Intestinal Macrophages in Inflammatory Bowel Diseases
}

\author{
Anja A. Kühl',2, Ulrike Erben ${ }^{1,2}$, Lea I. Kredel ${ }^{1}$ and Britta Siegmund ${ }^{1,2 *}$ \\ 'Division of Gastroenterology, Infectious Diseases and Rheumatology, Medical Department, Charité - Universitätsmedizin \\ Berlin, Berlin, Germany, ${ }^{2}$ Research Center ImmunoSciences, Charité - Universitätsmedizin Berlin, Berlin, Germany
}

Macrophages as innate immune cells and fast responders to antigens play a central role in protecting the body from the luminal content at a huge interface. Chronic inflammation in inflammatory bowel diseases massively alters the number and the subset diversity of intestinal macrophages. We here address the diversity within the human intestinal macrophage compartment at the level of similarities and differences between homeostasis and chronic intestinal inflammation as well as between UC and CD, including the potential role of macrophage subsets for intestinal fibrosis. Hallmark of macrophages is their enormous plasticity, i.e., their capacity to integrate signals from their environment thereby changing their phenotype and functions. Tissue-resident macrophages located directly beneath the surface epithelium in gut homeostasis are mostly tolerogenic. The total number of macrophages increases with luminal contents entering the mucosa through a broken intestinal barrier in ulcerative colitis (UC) as well as in Crohn's disease (CD). Although not fully understood, the resulting mixtures of tissue-resident and tis-

Edited by:

Tarcio Teodoro Braga,

University of São Paulo, Brazil

Reviewed by:

Benoit Chassaing,

Georgia State University, USA

Michael Scharl,

University Hospital Zürich,

Switzerland

${ }^{*}$ Correspondence:

Britta Siegmund

britta.siegmund@charite.de

Specialty section:

This article was submitted to

Molecular Innate Immunity,

a section of the journal

Frontiers in Immunology

Received: 31 October 2015 Accepted: 22 November 2015 Published: 07 December 2015

Citation:

Kühl AA, Erben U, Kredel LI and Siegmund B (2015) Diversity of

Intestinal Macrophages in Inflammatory Bowel Diseases.

Front. Immunol. 6:613. doi: 10.3389/fimmu.2015.00613 sue-infiltrating macrophages in both entities are diverse with respect to their phenotypes and their distribution. Macrophages in UC mainly act within the intestinal mucosa. In $\mathrm{CD}$, macrophages can also be found in the muscularis and the mesenteric fat tissue compartment. Taken together, the present knowledge on human intestinal macrophages so far provides a good starting point to dig deeper into the similarities and differences of functional subsets and to finally use their phenotypical diversity as markers for complex local milieus in health and disease.

Keywords: intestinal macrophages, gut homeostasis, inflammatory bowel diseases, fibrosis, diversity

\section{INTRODUCTION}

The gastrointestinal tract is the largest immune compartment of the human body. The major function of the intestinal immune cells is to maintain the integrity of the body at the huge interface between external stimuli that include food components and the intestinal microflora. Chronic inflammation in inflammatory bowel diseases (IBD) profoundly alters the composition of all local immune-cell compartments. Macrophages are part of the innate immune system and instrumental in controlling the barrier function in the small and the large intestine. The macrophages integrate signals

\footnotetext{
Abbreviations: ALDH, aldehyde dehydrogenase; CD, Crohn's disease; CCL, C-C chemokine ligand; CLR, C-type-lectin-like receptor; CX3CR1, chemokine (C-X3-C motif) receptor 1; HLA, human leukocyte antigen; IBD, inflammatory bowel disease; Ig, immunoglobulin; MMP, matrix metalloproteinase; NF- $\mathrm{kB}$, nuclear factor kappa-light-chain enhancer of activated B cells; NOD, nucleotide-binding oligomerization domain; NLR, NOD-like receptor; PRR, pattern recognition receptors; TLR, tolllike-receptor; TREM, triggering receptor expressed on myeloid cells; UC, ulcerative colitis.
} 
from their environment, thereby changing their phenotype and function. The present knowledge about intestinal macrophages is predominantly based on mouse studies. Even the finding of the gut as the largest reservoir of tissue-resident macrophages within the body (1) remains to be verified for men. This minireview deliberately restricts to systematic human studies. Only if such data were lacking, we included findings from animal models that might be relevant for the human mucosal surface. Differences in between mice and men will be highlighted. Non-inflamed tissue areas neighboring the inflamed areas in ulcerative colitis (UC) and Crohn's disease (CD), the main forms of IBD, represent rather homeostatic conditions. Hence, the diversity within the human intestinal macrophage compartment at the level of similarities and differences between homeostasis and chronic intestinal inflammation as well as between UC and CD, including the potential role of macrophage subsets for intestinal fibrosis, will be discussed.

\section{INTESTINAL MACROPHAGES IN GUT HOMEOSTASIS AND IN IBD}

In terms of a first-line defense, tissue-resident intestinal macrophages contribute to the gut homeostasis by eliminating invading pathogens without inducing an inflammatory response of the lymphocytes within the lamina propria. Positioned directly beneath the surface epithelium, the macrophages in intestinal tissues are the first immune-cell population encountering foreign material, e.g., luminal bacteria or food antigens randomly passing the epithelial barrier (Figure 1A). Whether human macrophages are able to sample luminal antigen by extending their dendrites between the epithelial cells reaching into the gut lumen as shown for mouse macrophages $(2,3)$ is unknown. On the one hand, intestinal macrophages are tolerant toward foreign matter by down-regulation of recognition receptors (4). On the other hand, intestinal macrophages that recognize food-derived antigens or commensal microbiota present the processed antigens in a tolerizing manner in the absence of co-stimulatory signals (5). Also to fulfill the task of protecting from unwanted immune responses and different from peripheral monocytes, stimulation via pattern recognition receptors (PRR) on resident macrophages results in low cytokine secretion and strong bactericidal activity (6). This increased bacterial clearance is associated with increased metallothionein expression, which is regulated by nuclear factor kappa-light-chain enhancer of activated B cells (NF- $\kappa \mathrm{B}$ ) and by caspase-1 (7).

Precursors of tissue-resident intestinal macrophages are bone marrow-derived monocytes, which circulate through the blood before recruitment into the intestinal mucosa by interleukin (IL) -8 and transforming growth factor (TGF) $\beta$ (8). These freshly recruited monocytes exhibit an inflammatory phenotype and exert inflammatory functions. Signals from the intestinal mucosa subsequently polarize them into inflammation anergic macrophages, e.g., by stromal TGF $\beta$-induced inhibition of NF- $\kappa$ B activation (9). Additionally, TGF $\beta$ and IL-10 induce down-regulation of triggering receptor expressed on myeloid cells (TREM)-1 on intestinal macrophages, a receptor that potently amplifies inflammatory

\section{A Gut homeostasis}
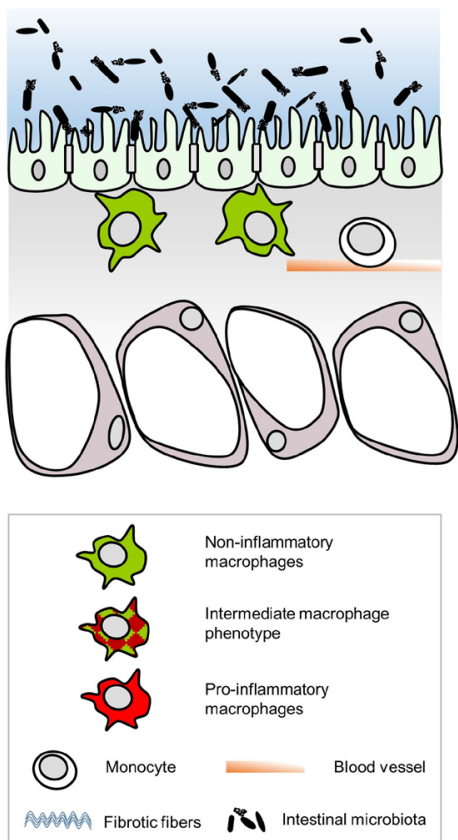

B Ulcerative colitis

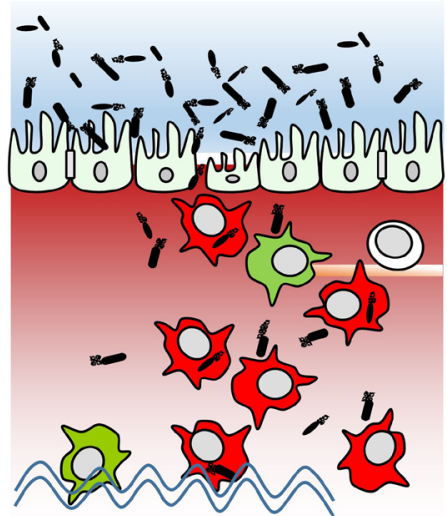

Mesenteric fat tissue

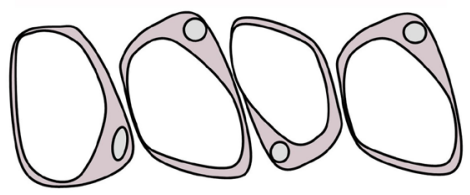

c Crohn's disease

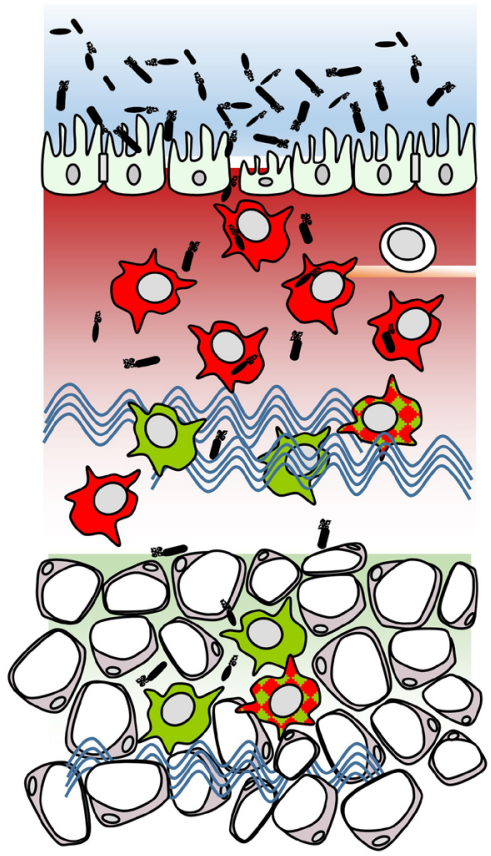

FIGURE 1 | Schematic summary of the relative intestinal macrophage-subtype distribution in (A) gut homeostasis or (B) ulcerative colitis and (C) Crohn's disease. 
reactions (10). A minority of tissue-resident intestinal macrophages express CD14 as well as CD11c involved in sensing of bacterial lipopolysaccharides (LPS) and are considered to be differentiation intermediaries (11). Blood monocytes have a life span of 3-4 days, while the life span of intestinal macrophages is unknown. In mice, intestinal macrophages lost upon senescence or apoptosis are constantly replenished by newly recruited blood monocytes and by cell division in situ (12). While mouse macrophages replenish in the intestine by recruitment of circulating cells and proliferation $(12,13)$, human intestinal macrophages fail to do so (8). Again in mice, mucosal tolerance is mediated by intestinal macrophages secreting IL-10, thereby expanding regulatory T cells (Tregs) (14). By contrast, human macrophages isolated from healthy jejunum and stimulated, e.g., with LPS, Helicobacter pylori urease, heat-killed Staphylococcus aureus, interferon (IFN) $\gamma$ or phorbol myristate acetate in vitro did not produce IL-10 (6).

A hallmark of macrophages is their plasticity as well as the ability to change phenotype and function according to the immediate environment. This has been demonstrated systemically by recent work from Xue and colleagues who defined a core transcriptome network for human and murine macrophages (15).

Hence, it is not surprising that small intestinal macrophages are different from large intestinal macrophages. These two organs have a distinct architecture, exert different functions, and host diverse microbiota. For example, macrophages from healthy jejunum show high expression of human leukocyte antigen (HLA)-DR and very low expression of CD14 and the low-affinity human immunoglobulin (Ig)G receptor CD16 (6), whereas in colonic macrophages low levels of CD14 and CD16 are accompanied by moderately expressed HLA-DR (16). Very early work, e.g., uses the activities of acid phosphatase and nonspecific esterase to distinguish macrophage subtypes (17). Here, tissue-resident intestinal macrophages directly underneath the epithelium differ from macrophages positioned deeper in the lamina propria with no implication that these cells abandon their tolerogenic potential (17).

Following the M1-M2 paradigm, which mirrors the polarization of $\mathrm{T}$ helper cells, macrophages are classified as pro-inflammatory M1 macrophages and anti-inflammatory M2 macrophages (18). Adhering to this model, tissue-resident macrophages are considered to be M2 macrophages $(19,20)$. In IBD, macrophages massively infiltrate the intestinal mucosa and present phenotypes and distribution distinct from tissue-resident macrophages in homeostasis. In CD patients, macrophages also infiltrate the muscular layer and the mesenteric fat $(17,21)$. At first sight, large numbers of $\mathrm{CD}^{+} 8^{+}$macrophages massively infiltrate the intestinal mucosa in IBD and diffusely spread throughout the thickened mucosa and submucosa but differ with regard to the subset composition and function in UC (Figure 1B) and CD (Figure 1C). Analyses of blood monocytes derived from CD patients reveal a reduction of classical monocytes $\left(\mathrm{CD} 14^{\mathrm{hi}} \mathrm{CD} 16^{-}\right)$, while intermediate monocytes $\left(\mathrm{CD} 14^{\mathrm{hi}} \mathrm{CD} 16^{+}\right)$were increased $(22,23)$. Extensive migration of classical monocytes toward the $\mathrm{C}-\mathrm{C}$ chemokine ligand (CCL) 2 in vitro and massively enhanced $\mathrm{CD} 14^{\text {hi }}$ macrophages in the ileal and the colonic mucosa of the CD patients led to the conclusion that peripheral classical monocytes immigrated into the intestinal mucosa (23). These newly recruited macrophages express high levels of CD33, of the high-affinity human IgG receptor CD64 and of the G-protein-coupled fractalkine receptor CX3CR1 but were HLA-DR ${ }^{\mathrm{dim}}$ (23). Infiltrating intestinal macrophages are distinct in phenotype and function from their resident counterparts. For example, tissue-infiltrating intestinal macrophages strongly express CD14 (24), TREM-1 and the human myeloid IgA Fc receptor CD89 (25) as well as activated NF- $\kappa B$ (26). Additionally, tissue-infiltrating intestinal macrophages secrete pro-inflammatory cytokines such as TNF, IL-6, IL-8, IL-23, IL-1 $\beta$, and IFN $\gamma$ as well as the chemokine CCL2 attracting monocytes $(25,27)$. This pro-inflammatory macrophage phenotype might result from polarization of any monocytic cell entering the pro-inflammatory environment of the inflamed intestinal mucosa. In line with this, the conditioning of newly recruited monocytes toward inflammation anergic M2 macrophages might be disturbed in IBD patients due to defective TGF $\beta$ signaling (28). In IBD, a broken epithelial barrier allows luminal content to enter the lamina propria, thereby triggering the inflammatory response of the lamina propria leukocytes. For recognition of microbiota, macrophages up-regulate PRR, including membrane-bound toll-like-receptors (TLR) and C-type-lectinlike receptors (CLR) as well as cytoplasmic nucleotide-binding oligomerization domain-containing protein (NOD)-like receptors (NLR) and retinoic acid-inducible gene-I-like receptors. Human PRR show less variants than those in mice; 10 TLR and 22 NLR are known in men compared to 13 TLR and 34 NLR in mice. Tissue-infiltrating macrophages in the inflamed colon mucosa predominantly express TLR2, TLR4, and TLR5 responding to bacterial peptidoglycans, LPS, and bacterial flagella (29). CLR bind a variety of carbohydrate ligands but only collectins function in terms of PRR (30). NOD2 recognizing muramyl dipeptide on Gram-positive and -negative bacteria is expressed in monocytes and Paneth cells but not in intestinal macrophages (31). In vitro studies showed that NOD2 level declined during differentiation of monocytes into macrophages (31). CARD15 coding for the caspase-recruitment domain of NOD proteins is highly upregulated in colonic macrophages of $\mathrm{CD}$ patients (32). So far it is not clear whether in chronic inflammation in CD the downregulation of NOD2 in monocytes infiltrating the colon mucosa is affected or whether resident macrophages up-regulated NOD2 expression. A missense mutation in the coding sequence of NOD2 was found in $17 \%$ of CD patients and in $4 \%$ of UC patients (33). As over 200 genes have been linked to IBD (34) and many of them are associated with macrophage functions (35-39), these immune cells present one cell population contributing to the pathogenesis of UC and CD.

\section{DIVERSITY WITHIN INTESTINAL MACROPHAGE COMPARTMENTS IN ULCERATIVE COLITIS AND CROHN'S DISEASE}

Above, we highlighted differences in the macrophage compartments and differentiated between tissue-resident and tissue-infiltrating macrophages in gut homeostasis and IBD. Additionally, the composition and functions of intestinal macrophages also differ in the inflamed gut of $\mathrm{UC}$ and $\mathrm{CD}$ patients, while overall macrophage 
numbers are comparable. So the question arises whether distinct macrophage subpopulations and distributions of these subtypes within the inflamed tissue areas might explain the overall different outcome in CD and UC. As for similarities in the local distribution, monocytes and M1 macrophages directly contribute to the defect of the barrier in IBD and large numbers of pro-inflammatory macrophages reside in the inflamed mucosa (40).

Over a decade ago, CD has even been referred to as a macrophage primary immunodeficiency (41). While this statement might simplify the overall interaction of immune cells in the mucosa, several facts add to this hypothesis. Thus, impaired bacterial clearance in CD has been attributed to defective cytokine secretion by macrophages (42). E. coli is commonly found within intestinal macrophages in CD (43), a dysfunction not reported for UC. On the contrary, macrophages of UC patients exuberantly and protractedly respond toward bacteria (44). This difference in bacterial clearance is also reflected by the formation of granulomas in CD but not UC $(45,46)$. Granulomas are formed when the effective eradication of invading pathogens fails.

Tissue-resident intestinal macrophages express the scavenger receptor CD163 that also recognizes Gram-positive and -negative bacteria $(47,48)$. While CD163 was initially thought to be exclusively expressed on noninflammatory M2 macrophages (49, 50 ), CD163 is expressed on resident macrophages of all normal tissues except on splenic white pulp macrophages and on germinal center macrophages (51). $\mathrm{CD}_{163^{+}}$macrophages are enriched in the peripheral blood as well as in the colonic mucosa of IBD patients (52-54). As CD163 is cleaved by metalloproteinases (MMPs) and shed from macrophages upon activation, soluble CD163 is an appropriate marker for macrophage activation (55). Compared to healthy controls, sCD163 is increased in UC and $\mathrm{CD}$ patients (56). In line with comparable numbers of macrophages in the intestinal mucosa in CD and UC, sCD163 levels are comparable in both entities (56). Upon successful treatment with glucocorticoids or TNF $\alpha$-antibodies, histomorphologically reflected by reduced macrophages in colon biopsies (57), serum sCD163 levels are reduced $(56,58)$.

No differences were found regarding the numbers of TREM-1 ${ }^{+}$ macrophages triggered to high production of pro-inflammatory cytokines (25) or in the expression of the co-stimulatory molecules CD80 and CD86 (5).

Aldehyde dehydrogenase $(\mathrm{ALDH})$ is involved in the release of retinoic acid, which has immunomodulatory properties and is mandatory in the induction of forkhead-box protein $3^{+}$Tregs $(59,60)$. Directly relating to Treg numbers in the colonic mucosa, $\mathrm{ALDH}^{+}$macrophages are reduced in the intestinal mucosa of $\mathrm{UC}$ but not of CD patients (61). While Treg numbers are generally increased in intestinal tissues from IBD patients compared to those of healthy controls, the numbers are lower in UC compared to $\mathrm{CD}(62,63)$. Taking into account that the composition of macrophage subpopulations might mirror the local environment, these findings suggest rather pro- than anti-inflammatory macrophage subpopulations involved in UC.

Specific for CD and relying on the presence of numerous M2 macrophages, the hyperplastic mesenteric fat tissue beyond the transmural inflammation could be defined as a second protective barrier from invading luminal contents (21). In the liver, macrophages are the master regulators of fibrosis (64). Large numbers of macrophages are found in fibrotic lesions of CD patients (65). Gene polymorphisms associated with the fibrostenotic phenotype in IBD like the V249I polymorphism of CX3CR1 and the T300A mutation in the autophagy-related ATG16L1 link to macrophage functions $(66,67)$. An indication for the involvement of distinct macrophage subpopulations in IBD is the development of fibrosis that is more pronounced in CD than in UC (68-70). Fibrosis and subsequent fibrotic strictures result from excessive wound-healing processes. Intestinal wound healing involves various steps with macrophages involved in all of these steps. In the early phase, inflammatory macrophages clear the wound from bacteria and cellular debris; in later phases, wound-healing M2 macrophages promote tissue remodeling. Tissue-resident intestinal macrophages express matrix MMP-2 (71) that takes part in the breakdown of extracellular matrix. In fibrotic CD, MMP2 is increased in the mucosa compared to that of healthy persons (72). The tyrosine-protein kinase Hck, a master regulator for human M2 macrophages (73) regulates myeloproliferation in mice (74). Other studies in mice showed that noninflammatory macrophages are involved at many levels in the whole wound-healing process, i.e., in wound closure, in formation of granulation tissue, in angiogenesis, in collagen synthesis, and in the production of growth factors (75). The pleiotropic cytokine IL-13 was also identified as a pro-fibrotic factor in CD (72). In combination with TNF $\alpha$, IL-13 induces TGF $\beta$ production in macrophages (76).

Macrophages carrying the mannose receptor CD206 and considered wound-healing macrophages (77) are increased in the injured mucosa of UC patients (78). The expression of the protooncogene protein Wnt1 by CD206 ${ }^{+}$macrophages enhanced the proliferation of stem cells in response to the epithelial injury in UC (78). Relating to the increased risk of cancer development upon long-standing IBD, large numbers of CD206 ${ }^{+}$macrophages are found in colorectal cancer (79).

Taken together, many open questions remain with regard to specifics of the involvement of different subpopulations of human macrophages in the pathogenesis and the chronicity of UC and CD. Further dissecting the diversity and the local distribution of functional macrophages in human gut tissues will help to define the clinical relevance of the macrophage subset.

\section{AUTHOR CONTRIBUTIONS}

AK, UE, LK, and BS summarized the content of the manuscript. $\mathrm{AK}$ and UE wrote the manuscript, and BS and LK discussed and edited the manuscript.

\section{ACKNOWLEDGMENTS}

This work was supported by the Deutsche Forschungsgemeinschaft.

\section{FUNDING}

BS received funding from the Deutsche Forschungsgemeinschaft: SPP1656, SFB633, SI-749/7-1. AAK received funding from the Deutsche Forschungsgemeinschaft: SFB633, SFB650. 


\section{REFERENCES}

1. Lee SH, Starkey PM, Gordon S. Quantitative analysis of total macrophage content in adult mouse tissues. Immunochemical studies with monoclonal antibody F4/80. J Exp Med (1985) 161:475-89.

2. Schulz O, Jaensson E, Persson EK, Liu X, Worbs T, Agace WW, et al. Intestinal CD103+, but not CX3CR1+, antigen sampling cells migrate in lymph and serve classical dendritic cell functions. J Exp Med (2009) 206:3101-14. doi:10.1084/jem.20091925

3. Farache J, Zigmond E, Shakhar G, Jung S. Contributions of dendritic cells and macrophages to intestinal homeostasis and immune defense. Immunol Cell Biol (2013) 91:232-9. doi:10.1038/icb.2012.79

4. Smith PD, Smythies LE, Mosteller-Barnum M, Sibley DA, Russell MW, Merger $\mathrm{M}$, et al. Intestinal macrophages lack CD14 and CD89 and consequently are down-regulated for LPS- and IgA-mediated activities. JImmunol (2001) 167:2651-6. doi:10.4049/jimmunol.167.5.2651

5. Rugtveit J, Bakka A, Brandtzaeg P. Differential distribution of B7.1 (CD80) and B7.2 (CD86) costimulatory molecules on mucosal macrophage subsets in human inflammatory bowel disease (IBD). Clin Exp Immunol (1997) 110:104-13. doi:10.1111/j.1365-2249.1997.507-ce1404.x

6. Smythies LE, Sellers M, Clements RH, Mosteller-Barnum M, Meng G, Benjamin WH, et al. Human intestinal macrophages display profound inflammatory anergy despite avid phagocytic and bacteriocidal activity. J Clin Invest (2005) 115:66-75. doi:10.1172/JCI200519229

7. Lahiri A, Abraham C. Activation of pattern recognition receptors up-regulates metallothioneins, thereby increasing intracellular accumulation of zinc, autophagy, and bacterial clearance by macrophages. Gastroenterology (2014) 147:835-46. doi:10.1053/j.gastro.2014.06.024

8. Smythies LE, Maheshwari A, Clements R, Eckhoff D, Novak L, Vu HL, et al. Mucosal IL-8 and TGF-beta recruit blood monocytes: evidence for cross-talk between the lamina propria stroma and myeloid cells. J Leukoc Biol (2006) 80:492-9. doi:10.1189/jlb.1005566

9. Smythies LE, Shen R, Bimczok D, Novak L, Clements RH, Eckhoff DE, et al. Inflammation anergy in human intestinal macrophages is due to Smadinduced IkappaBalpha expression and NF-kappaB inactivation. J Biol Chem (2010) 285:19593-604. doi:10.1074/jbc.M109.069955

10. Schenk M, Bouchon A, Birrer S, Colonna M, Mueller C. Macrophages expressing triggering receptor expressed on myeloid cells-1 are underrepresented in the human intestine. J Immunol (2005) 174:517-24. doi:10.4049/ jimmunol.174.1.517

11. Bain CC, Scott CL, Uronen-Hansson H, Gudjonsson S, Jansson O, Grip O, et al. Resident and pro-inflammatory macrophages in the colon represent alternative context-dependent fates of the same Ly6Chi monocyte precursors. Mucosal Immunol (2013) 6:498-510. doi:10.1038/mi.2012.89

12. Jenkins SJ, Ruckerl D, Cook PC, Jones LH, Finkelman FD, Van Rooijen N, et al. Local macrophage proliferation, rather than recruitment from the blood, is a signature of TH2 inflammation. Science (2011) 332:1284-8. doi:10.1126/ science. 1204351

13. Bain CC, Bravo-Blas A, Scott CL, Gomez Perdiguero E, Geissmann F, Henri S, et al. Constant replenishment from circulating monocytes maintains the macrophage pool in the intestine of adult mice. Nat Immunol (2014) 15:929-37. doi:10.1038/ni.2967

14. Hadis U, Wahl B, Schulz O, Hardtke-Wolenski M, Schippers A, Wagner N, et al. Intestinal tolerance requires gut homing and expansion of FoxP3+ regulatory T cells in the lamina propria. Immunity (2011) 34:237-46. doi:10.1016/j. immuni.2011.01.016

15. Xue J,SchmidtSV, Sander J, Draffehn A, Krebs W, Quester I, et al. Transcriptomebased network analysis reveals a spectrum model of human macrophage activation. Immunity (2014) 40:274-88. doi:10.1016/j.immuni.2014.01.006

16. Rogler G, Hausmann M, Vogl D, Aschenbrenner E, Andus T, Falk W, et al. Isolation and phenotypic characterization of colonic macrophages. Clin Exp Immunol (1998) 112:205-15. doi:10.1046/j.1365-2249.1998.00557.x

17. Mahida YR, Patel S, Gionchetti P, Vaux D, Jewell DP. Macrophage subpopulations in lamina propria of normal and inflamed colon and terminal ileum. Gut (1989) 30:826-34. doi:10.1136/gut.30.6.826

18. Mantovani A, Sica A, Sozzani S, Allavena P, Vecchi A, Locati M. The chemokine system in diverse forms of macrophage activation and polarization. Trends Immunol (2004) 25:677-86. doi:10.1016/j.it.2004.09.015
19. Davies LC, Jenkins SJ, Allen JE, Taylor PR. Tissue-resident macrophages. Nat Immunol (2013) 14:986-95. doi:10.1038/ni.2705

20. Mantovani A, Biswas SK, Galdiero MR, Sica A, Locati M. Macrophage plasticity and polarization in tissue repair and remodelling. J Pathol (2013) 229:176-85. doi:10.1002/path.4133

21. Kredel LI, Batra A, Stroh T, Kuhl AA, Zeitz M, Erben U, et al. Adipokines from local fat cells shape the macrophage compartment of the creeping fat in Crohn's disease. Gut (2013) 62:852-62. doi:10.1136/gutjnl-2011-301424

22. Koch S, Kucharzik T, Heidemann J, Nusrat A, Luegering A. Investigating the role of proinflammatory $\mathrm{CD} 16+$ monocytes in the pathogenesis of inflammatory bowel disease. Clin Exp Immunol (2010) 161:332-41. doi:10.1111/j.1365-2249.2010.04177.x

23. Thiesen S, Janciauskiene S, Uronen-Hansson H, Agace W, Hogerkorp CM, Spee P, et al. CD14(hi)HLA-DR(dim) macrophages, with a resemblance to classical blood monocytes, dominate inflamed mucosa in Crohn's disease. $J$ Leukoc Biol (2014) 95:531-41. doi:10.1189/jlb.0113021

24. Grimm MC, Pavli P, Van De Pol E, Doe WF. Evidence for a CD14+ population of monocytes in inflammatory bowel disease mucosa - implications for pathogenesis. Clin Exp Immunol (1995) 100:291-7. doi:10.1111/j.1365-2249.1995. tb03667.x

25. Schenk M, Bouchon A, Seibold F, Mueller C. TREM-1 - expressing intestinal macrophages crucially amplify chronic inflammation in experimental colitis and inflammatory bowel diseases. J Clin Invest (2007) 117:3097-106. doi:10.1172/JCI30602

26. Rogler G, Brand K, Vogl D, Page S, Hofmeister R, Andus T, et al. Nuclear factor kappaB is activated in macrophages and epithelial cells of inflamed intestinal mucosa. Gastroenterology (1998) 115:357-69. doi:10.1016/ S0016-5085(98)70202-1

27. Kamada N, Hisamatsu T, Okamoto S, Chinen H, Kobayashi T, Sato T, et al. Unique CD14 intestinal macrophages contribute to the pathogenesis of Crohn disease via IL-23/IFN-gamma axis. J Clin Invest (2008) 118:2269-80. doi:10.1172/JCI34610

28. Monteleone G, Kumberova A, Croft NM, Mckenzie C, Steer HW, Macdonald TT. Blocking Smad7 restores TGF-betal signaling in chronic inflammatory bowel disease. J Clin Invest (2001) 108:601-9. doi:10.1172/ JCI12821

29. Hausmann M, Kiessling S, Mestermann S, Webb G, Spottl T, Andus T, et al. Toll-like receptors 2 and 4 are up-regulated during intestinal inflammation. Gastroenterology (2002) 122:1987-2000. doi:10.1053/gast.2002.33662

30. Zelensky AN, Gready JE. The C-type lectin-like domain superfamily. FEBS J (2005) 272:6179-217. doi:10.1111/j.1742-4658.2005.05031.x

31. Lala S, Ogura Y, Osborne C, Hor SY, Bromfield A, Davies S, et al. Crohn's disease and the NOD2 gene: a role for paneth cells. Gastroenterology (2003) 125:47-57. doi:10.1016/S0016-5085(03)00661-9

32. Berrebi D, Maudinas R, Hugot JP, Chamaillard M, Chareyre F, De Lagausie $\mathrm{P}$, et al. Card15 gene overexpression in mononuclear and epithelial cells of the inflamed Crohn's disease colon. Gut (2003) 52:840-6. doi:10.1136/ gut.52.6.840

33. Hugot JP, Chamaillard M, Zouali H, Lesage S, Cezard JP, Belaiche J, et al. Association of NOD2 leucine-rich repeat variants with susceptibility to Crohn's disease. Nature (2001) 411:599-603. doi:10.1038/35079107

34. Liu JZ, Van Sommeren S, Huang H, Ng SC, Alberts R, Takahashi A, et al. Association analyses identify 38 susceptibility loci for inflammatory bowel disease and highlight shared genetic risk across populations. Nat Genet (2015) 47:979-86. doi:10.1038/ng.3359

35. Hoffman HM, Mueller JL, Broide DH, Wanderer AA, Kolodner RD. Mutation of a new gene encoding a putative pyrin-like protein causes familial cold autoinflammatory syndrome and Muckle-Wells syndrome. Nat Genet (2001) 29:301-5. doi:10.1038/ng756

36. Fisher SA, Lewis CM. Power of genetic association studies in the presence of linkage disequilibrium and allelic heterogeneity. Hum Hered (2008) 66:210-22. doi:10.1159/000143404

37. Villani AC, Lemire M, Fortin G, Louis E, Silverberg MS, Collette C, et al. Common variants in the NLRP3 region contribute to Crohn's disease susceptibility. Nat Genet (2009) 41:71-6. doi:10.1038/ng.285

38. Jostins L, Ripke S, Weersma RK, Duerr RH, Mcgovern DP, Hui KY, et al. Hostmicrobe interactions have shaped the genetic architecture of inflammatory bowel disease. Nature (2012) 491:119-24. doi:10.1038/nature11582 
39. Hedl M, Abraham C. A TNFSF15 disease-risk polymorphism increases pattern-recognition receptor-induced signaling through caspase-8-induced IL-1. Proc Natl Acad Sci U S A (2014) 111:13451-6. doi:10.1073/ pnas. 1404178111

40. Lissner D, Schumann M, Batra A, Kredel LI, Kuhl AA, Erben U, et al. Monocyte and M1 macrophage-induced barrier defect contributes to chronic intestinal inflammation in IBD. Inflamm Bowel Dis (2015) 21:1297-305. doi:10.1097/ MIB.0000000000000384

41. Casanova JL, Abel L. Revisiting Crohn's disease as a primary immunodeficiency of macrophages. J Exp Med (2009) 206:1839-43. doi:10.1084/ jem.20091683

42. Smith AM, Rahman FZ, Hayee B, Graham SJ, Marks DJ, Sewell GW, et al. Disordered macrophage cytokine secretion underlies impaired acute inflammation and bacterial clearance in Crohn's disease. J Exp Med (2009) 206:1883-97. doi:10.1084/jem.20091233

43. Elliott TR, Rayment NB, Hudspith BN, Hands RE, Taylor K, Parkes GC, et al. Lamina propria macrophage phenotypes in relation to Escherichia coli in Crohn's disease. BMC Gastroenterol (2015) 15:75. doi:10.1186/ s12876-015-0305-3

44. Rahman FZ, Smith AM, Hayee B, Marks DJ, Bloom SL, Segal AW. Delayed resolution of acute inflammation in ulcerative colitis is associated with elevated cytokine release downstream of TLR4. PLoS One (2010) 5:e9891. doi:10.1371/ journal.pone.0009891

45. Cook MG, Dixon MF. An analysis of the reliability of detection and diagnostic value of various pathological features in Crohn's disease and ulcerative colitis. Gut (1973) 14:255-62. doi:10.1136/gut.14.4.255

46. Rotterdam H, Korelitz BI, Sommers SC. Microgranulomas in grossly normal rectal mucosa in Crohn's disease. Am J Clin Pathol (1977) 67:550-4.

47. Fabriek BO, Dijkstra CD, Van Den Berg TK. The macrophage scavenger receptor CD163. Immunobiology (2005) 210:153-60. doi:10.1016/j. imbio.2005.05.010

48. Fabriek BO, Van Bruggen R, Deng DM, Ligtenberg AJ, Nazmi K, Schornagel $\mathrm{K}$, et al. The macrophage scavenger receptor CD163 functions as an innate immune sensor for bacteria. Blood (2009) 113:887-92. doi:10.1182/ blood-2008-07-167064

49. Buechler C, Ritter M, Orso E, Langmann T, Klucken J, Schmitz G. Regulation of scavenger receptor CD163 expression in human monocytes and macrophages by pro- and antiinflammatory stimuli. J Leukoc Biol (2000) 67:97-103.

50. Gordon S. Alternative activation of macrophages. Nat Rev Immunol (2003) 3:23-35. doi:10.1038/nri978

51. Lau SK, Chu PG, Weiss LM. CD163: a specific marker of macrophages in paraffin-embedded tissue samples. Am J Clin Pathol (2004) 122:794-801. doi:10.1309/QHD6YFN81KQXUUH6

52. Demetter P, De Vos M, Van Huysse JA, Baeten D, Ferdinande L, Peeters H, et al. Colon mucosa of patients both with spondyloarthritis and Crohn's disease is enriched with macrophages expressing the scavenger receptor CD163. Ann Rheum Dis (2005) 64:321-4. doi:10.1136/ard.2003.018382

53. Barros MH, Hauck F, Dreyer JH, Kempkes B, Niedobitek G. Macrophage polarisation: an immunohistochemical approach for identifying M1 and M2 macrophages. PLoS One (2013) 8:e80908. doi:10.1371/journal.pone.0080908

54. Franze E, Caruso R, Stolfi C, Sarra M, Cupi ML, Caprioli F, et al. Lesional accumulation of CD163-expressing cells in the gut of patients with inflammatory bowel disease. PLoS One (2013) 8:e69839. doi:10.1371/journal.pone.0069839

55. Moller HJ. Soluble CD163. Scand J Clin Lab Invest (2012) 72:1-13. doi:10.31 09/00365513.2011.626868

56. Dige A, Stoy S, Thomsen KL, Hvas CL, Agnholt J, Dahlerup JF, et al. Soluble CD163, a specific macrophage activation marker, is decreased by anti-TNFalpha antibody treatment in active inflammatory bowel disease. Scand J Immunol (2014) 80:417-23. doi:10.1111/sji.12222

57. Caprioli F, Bose F, Rossi RL, Petti L, Vigano C, Ciafardini C, et al. Reduction of CD68+ macrophages and decreased IL-17 expression in intestinal mucosa of patients with inflammatory bowel disease strongly correlate with endoscopic response and mucosal healing following infliximab therapy. Inflamm Bowel Dis (2013) 19:729-39. doi:10.1097/MIB.0b013e318280292b

58. Moller HJ, Aerts H, Gronbaek H, Peterslund NA, Hyltoft Petersen P, Hornung N, et al. Soluble CD163: a marker molecule for monocyte/macrophage activity in disease. Scand J Clin Lab Invest Suppl (2002) 237:29-33. doi:10.1080/003655102762377466
59. Hill JA, Hall JA, Sun CM, Cai Q, Ghyselinck N, Chambon P, et al. Retinoic acid enhances Foxp3induction indirectlyby relieving inhibition from CD4+CD44hi Cells. Immunity (2008) 29:758-70. doi:10.1016/j.immuni.2008.09.018

60. Hall JA, Grainger JR, Spencer SP, Belkaid Y. The role of retinoic acid in tolerance and immunity. Immunity (2011) 35:13-22. doi:10.1016/j. immuni.2011.07.002

61. Magnusson MK, Brynjolfsson SF, Dige A, Uronen-Hansson H, Borjesson LG, Bengtsson JL, et al. Macrophage and dendritic cell subsets in IBD: ALDH cells are reduced in colon tissue of patients with ulcerative colitis regardless of inflammation. Mucosal Immunol (2015). doi:10.1038/mi.2015.48

62. Ban H, Andoh A, Shioya M, Nishida A, Tsujikawa T, Fujiyama Y. Increased number of FoxP3+CD4+ regulatory $\mathrm{T}$ cells in inflammatory bowel disease. Mol Med Rep (2008) 1:647-50. doi:10.3892/mmr_00000006

63. Lord JD, Valliant-Saunders K, Hahn H, Thirlby RC, Ziegler SF. Paradoxically increased FOXP3 $+\mathrm{T}$ cells in IBD do not preferentially express the isoform of FOXP3 lacking exon 2. Dig Dis Sci (2012) 57:2846-55. doi:10.1007/ s10620-012-2292-3

64. Wynn TA, Barron L. Macrophages: master regulators of inflammation and fibrosis. Semin Liver Dis (2010) 30:245-57. doi:10.1055/s-0030-1255354

65. Scharl M, Huber N, Lang S, Furst A, Jehle E, Rogler G. Hallmarks of epithelial to mesenchymal transition are detectable in Crohn's disease associated intestinal fibrosis. Clin Transl Med (2015) 4:1. doi:10.1186/s40169-015-0046-5

66. Sabate JM, Ameziane N, Lamoril J, Jouet P, Farmachidi JP, Soule JC, et al. The V249I polymorphism of the CX3CR1 gene is associated with fibrostenotic disease behavior in patients with Crohn's disease. Eur J Gastroenterol Hepatol (2008) 20:748-55. doi:10.1097/MEG.0b013e3282f824c9

67. Weersma RK, Stokkers PC, Van Bodegraven AA, Van Hogezand RA, Verspaget HW, De Jong DJ, et al. Molecular prediction of disease risk and severity in a large Dutch Crohn's disease cohort. Gut (2009) 58:388-95. doi:10.1136/ gut.2007.144865

68. Louis E, Collard A, Oger AF, Degroote E, Aboul Nasr El Yafi FA, Belaiche J. Behaviour of Crohn's disease according to the Vienna classification: changing pattern over the course of the disease. Gut (2001) 49:777-82. doi:10.1136/ gut.49.6.777

69. Van Assche G, Geboes K, Rutgeerts P. Medical therapy for Crohn's disease strictures. Inflamm Bowel Dis (2004) 10:55-60. doi:10.1097/00054725-200401000-00009

70. Yamagata M, Mikami T, Tsuruta T, Yokoyama K, Sada M, Kobayashi K, et al. Submucosal fibrosis and basic-fibroblast growth factor-positive neutrophils correlate with colonic stenosis in cases of ulcerative colitis. Digestion (2011) 84:12-21. doi:10.1159/000320773

71. Kirkegaard T, Hansen A, Bruun E, Brynskov J. Expression and localisation of matrix metalloproteinases and their natural inhibitors in fistulae of patients with Crohn's disease. Gut (2004) 53:701-9. doi:10.1136/gut.2003.017442

72. Bailey JR, Bland PW, Tarlton JF, Peters I, Moorghen M, Sylvester PA, et al. IL13 promotes collagen accumulation in Crohn's disease fibrosis by down-regulation of fibroblast MMP synthesis: a role for innate lymphoid cells? PLoS One (2012) 7:e52332. doi:10.1371/journal.pone.0052332

73. Bhattacharjee A, Pal S, Feldman GM, Cathcart MK. Hck is a key regulator of gene expression in alternatively activated human monocytes. J Biol Chem (2011) 286:36709-23. doi:10.1074/jbc.M111.291492

74. Xiao W, Hong H, Kawakami Y, Lowell CA, Kawakami T. Regulation of myeloproliferation and M2 macrophage programming in mice by Lyn/Hck, SHIP, and Stat5. J Clin Invest (2008) 118:924-34. doi:10.1172/JCI34013

75. Mirza R, Dipietro LA, Koh TJ. Selective and specific macrophage ablation is detrimental to wound healing in mice. Am J Pathol (2009) 175:2454-62. doi:10.2353/ajpath.2009.090248

76. Fichtner-Feigl S, Strober W, Kawakami K, Puri RK, Kitani A. IL-13 signaling through the IL-13alpha2 receptor is involved in induction of TGF-beta1 production and fibrosis. Nat Med (2006) 12:99-106. doi:10.1038/nm1332

77. Martinez FO, Helming L, Milde R, Varin A, Melgert BN, Draijer C, et al. Genetic programs expressed in resting and IL- 4 alternatively activated mouse and human macrophages: similarities and differences. Blood (2013) 121:e57-69. doi:10.1182/blood-2012-06-436212

78. Cosin-Roger J, Ortiz-Masia D, Calatayud S, Hernandez C, Alvarez A, Hinojosa J, et al. M2 macrophages activate WNT signaling pathway in epithelial cells: relevance in ulcerative colitis. PLoS One (2013) 8:e78128. doi:10.1371/journal. pone. 0078128 
79. Zhang Y, Sime W, Juhas M, Sjolander A. Crosstalk between colon cancer cells and macrophages via inflammatory mediators and CD47 promotes tumour cell migration. Eur J Cancer (2013) 49:3320-34. doi:10.1016/j.ejca.2013.06.005

Conflict of Interest Statement: The authors declare that the research was conducted in the absence of any commercial or financial relationships that could be construed as a potential conflict of interest.
Copyright (c) 2015 Kühl, Erben, Kredel and Siegmund. This is an open-access article distributed under the terms of the Creative Commons Attribution License (CC $B Y)$. The use, distribution or reproduction in other forums is permitted, provided the original author(s) or licensor are credited and that the original publication in this journal is cited, in accordance with accepted academic practice. No use, distribution or reproduction is permitted which does not comply with these terms. 